Title:

Rainfall and rainfall erosivity time series analysis of a small semi-arid watershed of the American Southwest

Author:

Meng Lu

Department of Physical Geography, Faculty of Geosciences, Utrecht University, Utrecht, The Netherlands. Email: $\underline{\text { m.lu@uu.nl }}$

Chris Renschler

Department of Geography, University at Buffalo, SUNY, NY, USA.

Email:rensch@buffalo.edu

The paper is a non-peer reviewed preprint submitted to EarthArXiv 


\title{
Rainfall and rainfall erosivity time series analysis of a small semi-arid watershed of the
}

\section{American Southwest}

\author{
Meng Lu ${ }^{1}$, Chris Renchler ${ }^{2}$
}

[1] Department of Physical Geography, Faculty of Geosciences, Utrecht University, Utrecht, The Netherlands

[2] Department of Geography, University at Buffalo, SUNY, NY, USA

\section{Rainfall and rainfall erosivity time series analysis of a small semi-arid watershed of the}

\section{American Southwest}

\author{
Meng Lu', Chris Renchler ${ }^{2}$
}

[1] Department of Physical Geography, Faculty of Geosciences, Utrecht University, Utrecht, The Netherlands

[2] Department of Geography, University at Buffalo, SUNY, NY, USA

\section{Abstract}

The long-term dense precipitation records provide important information to understand rainfall erosivity and soil erosion in semi-arid rangelands. This paper investigates the temporal trends of changes in rainfall, rainfall erosivity, and the responses of runoff and sediment on the WS103 watershed, a small semiarid rangeland watershed in the Walnut gulch Experimental Watershed, Tombstone, Arizona. A difficulty of analyzing long-term time series of rainfall characters and soil erosion indicators lies in the analogue-to-digital changing of rainfall gauge system in 1999. Extending from a previous research that compares the influence of system alteration to annual rainfall records and peak rainfall intensity, our study further compares event statistics: rainfall characters and rainfall erosivity per event, as well as number of events and significant events. After determining the influence of the digital-to-analogue system alteration to time series analysis, the time series structural stability is analyzed with a parametric and a non- 
parametric time series structural change detection methods. Finally, the trends of the time series of rainfall characters and theirs effects to soil erosion are quantified with the GLS (general least square) model.

Key words: precipitation event dynamics, rainfall erosivity, time series structural change, analogue-todigital system conversion, range-land rainfall gauge data. 


\section{Introduction}

Global climate change is expected to impact precipitation characteristics, such as precipitation amount, intensity, frequency and type (IPCC Climate Change 2007). The change in frequency and patterns of precipitation events are the most direct mechanisms to affect soil erosion and runoff worldwide, including in semiarid range and pasture lands (Nunes et al., 2009; Zhang et at., 2009; Goodrich et al., 2008b; Renard et al., 2008b; Nearing, 2001). Quantifying the temporal trends in event precipitation characteristics is thus important for analyzing climate effects on soil erosion and runoff. The detailed precipitation records collected on the US Department of Agriculture - Agricultural Research Service (USDA-ARS) Walnut Gulch Experimental Watershed (WGEW) offer the opportunity for the temporal quantification of precipitation events for the past 50 years. Previous analyses of observed long-term temporal variability of precipitation within the WGEW include Nichols et al. (2002) and Goodrich et al. (2008b). Nichols et al (2002) selected six rainfall gauges to represent the precipitation of the WGEW and analyzed the temporal precipitation trends from 1956 to 1996 at annual, seasonal and event scale. In the study of Goodrich et al. 2008, the six rainfall gauges explored in Nichols et al (2002) were extended spatially and temporally to include the entire rainfall gauge network and an additional ten years. Both of these studies investigated the precipitation trends and event characteristics on an annual basis. The significant temporal trends of annual and winter precipitation found by Nichols et al. (2002) were not reported in the study of Goodrich et al. (2008) when taking the additional ten years, which included a period of extreme drought, into account.

The rainfall erosivity is a measure of rainfall's ability to cause erosion when factors other than rainfall are held constant. The numerical values used for rainfall erosivity reflect the amount and rate of soil erosion that are likely to be associated with the raindrop energy and runoff. Many studies have focused on selecting appropriate rainfall erosivity factors (Dijk 2002). A direct computation of rainfall erosivity requires long-term data for both the rainfall amount and rainfall intensity. The properties of raindrops and 
kinetic energy are among the most frequently used parameters to develop erosivity indices. The most frequently used indices on rainfall erosivity are calculated as multiplication of rainfall amount and maximum rainfall intensity (i.e., rainfall erosivity $=$ rainfall amount $\times$ maximum rainfall intensity , Lal 1976), multiplication of kinetic energy (E) and 30 minutes (mins) peak rainfall intensity (I30) (E×I30, Wischmeier and Smith 1958), and total kinetic energy of all the rain falling at more than $25 \mathrm{~mm} / \mathrm{h}$ (Dijk, 2002). The accuracy of these $\mathrm{R}$ indices is affected by climate effects. For example, an erosivity index of the form Lal (1976) may give better correlations with soil loss amounts in the studied regions than the EI30 index if the total storm energy is almost directly proportional to rainfall amount (Hussein et al., 1994), or if the rainfall amount and intensity are lower (Kiassari et al., 2012).

The breakpoint and pluviograph data from WGEW allow for the accurate and consistent delineation of rainfall and runoff events, which are identified by the precise beginning and end time of the process. A rainfall event begins when the rain gage detects measurable rainfall, and two storm events are considered as separate events when a period of one hour or more are observed without rainfall (Goodrich et al., 2008a). A rainfall event is characterized by event precipitation amount, 30-mins event intensity, and event duration (Nichols et al., 2002), or time to peak, peak intensity, and storm duration (Nicks et al., 1995). A runoff event begins when the flume detects a measurable runoff, and two runoff events are considered as separate events when a period of one hour or more are observed without any runoff (Stone et al., 2008). The runoff event is characterized by a full hydrograph, which allows the comparison to simulations of volume of runoff, peak rate, and event duration (Stone et al., 2008).

Rainfall events that are most likely to generate runoff are called significant rainfall, and are determined when the I30 passes a threshold. The significant rainfall events are important in explaining the occurrences of runoff events (Osborn, 1969). The threshold of for a significant rainfall to occur may vary depending on the land cover type. In particular, Goodrich et al. (2008b) defined a threshold of $25 \mathrm{~mm} / \mathrm{h}$ 
for the WGEW. The objectives of this research are to investigate the effect of analogue-to-digital rainfall gauge conversion to long-term time series analysis and to analyze the time series structure and to quantify the temporal trends of rainfall event characters

\section{Data}

\subsection{Study Site}

The $150 \mathrm{~km}^{2}$-Walnut Gulch Experimental Watershed (WGEW) $\left(31.43^{\circ} \mathrm{N}, 110.410^{\circ} \mathrm{W}\right)$ (Figure 1.1) in southwestern Arizona, which is one of the two USDA-ARS Southwest Watershed Research Center (SWRC) experimental watersheds on western rangelands. WGEW is one of the most intensively instrumented semiarid experimental watersheds of the world (SWRC, 2011). Hydro-meteorological and soil erosion data are collected from 125 instrumented installations on the WGEW. Precipitation is measured with a network of 88 weighing type-recording rain gages distributed throughout the watershed (SWRC, 2011). WGEW is contained within the 7,600 $\mathrm{km}^{2}$ upper San Pedro River Basin, with the main channel of the watershed an ephemeral tributary of the San Pedro River. The primary land use is cattle grazing, with mining, limited urbanization and recreation consisting the remaining uses (SWRC, 2011). The mean annual temperature at the WGEW is approximately $18^{\circ} \mathrm{C}$, and approximately two-thirds of the annual precipitation occurs in the "monsoon" season from July to September (Nichols et al., 2002).

The study area is located in a 3.7 hectare (ha) shrub dominated, semiarid subwatershed of WGEW with the historical name Lucky Hills (Figure 1). As it is officially numbered 103 by SWRC, this subwatershed is called WS103 in this study. The WS103 is chosen because it has the most complete rainfall records compared to the other subwatersheds. The recorded mean annual precipitation measured at the WS103 was $292 \mathrm{~mm}$. The mean annual temperature is $17^{\circ} \mathrm{C}$ ranging from $1{ }^{\circ} \mathrm{C}$ in January to $35^{\circ} \mathrm{C}$ in June (Ritchie et al., 2005). The mean elevation of the WS103 watershed ranges from $1363 \mathrm{~m}$ to $1375 \mathrm{~m}$ (Ritchie et al., 
2005 ) and the mean hill slope gradients of the WS103 is $7.7 \%\left(4.4^{\circ}\right)$ (Nearing et al., 2005a). The canopy cover during the rainy season is approximately $25 \%$ and the ground has approximately two-thirds rock cover and one-third bare soil. Dominant shrubs include Creosote and Whitethorn. The soils are mapped as McNeal Gravelly Sandy Loam, with 25\% rock fragments in the surface area layer. The surface layer is composed of $60 \%$ sand, $25 \%$ silt, and $15 \%$ clay (Nearing et al., 2005b). The WS103 watershed has historically served as grazing land for cattle and horses but is too degraded to support vegetation sufficient for grazing today. Several causes for the general change from grasses to shrubs have been suggested including climatic, grazing, and fire (Nearing et al., 2005a). No major land cover change could be detected in the watershed since 1963 when the area was fenced. 


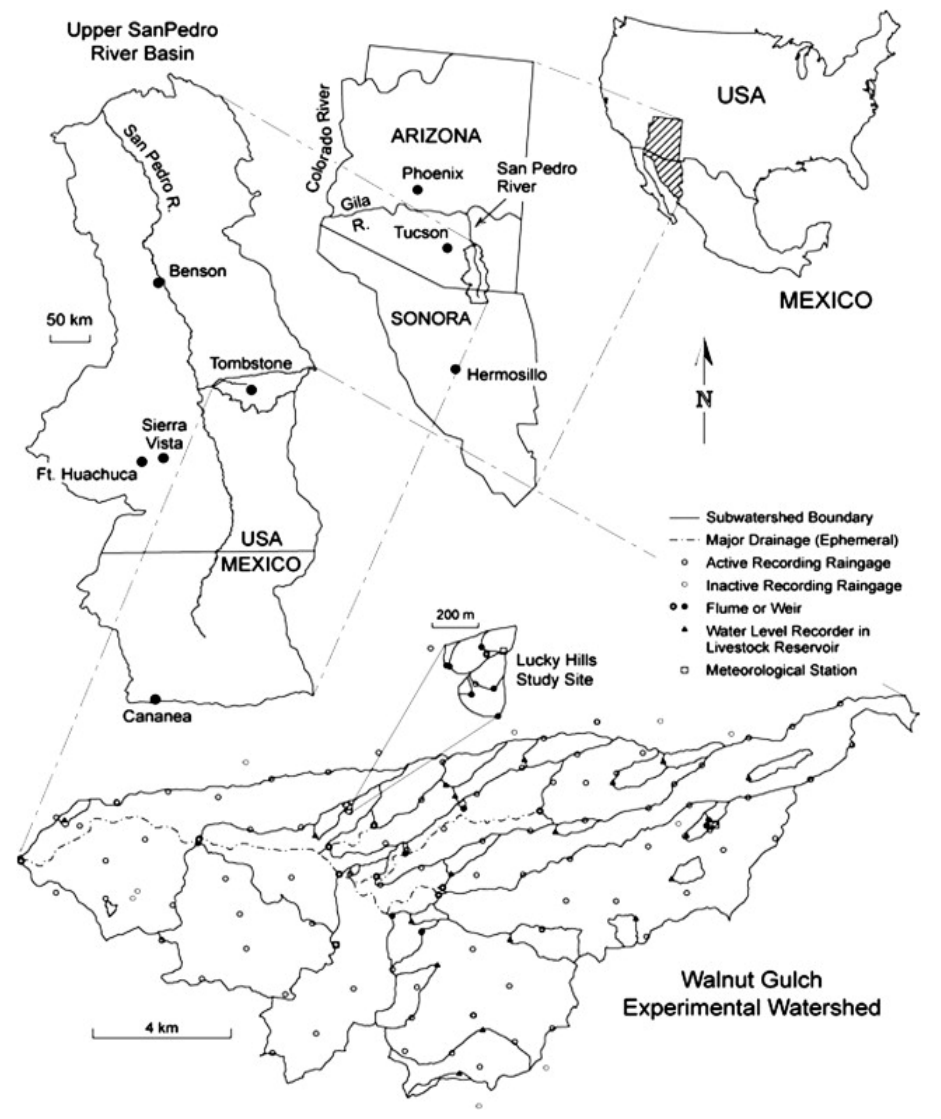

Figure 1 Map and location of Walnut Gulch Experimental Watershed, Tombstone, Arizona.

The dots indicate the distribution of rain gages and flumes as indicate in legend (adapted from USDA-ARS Southwestern Watershed Research Center website- $\underline{\text { http://www.tucson.ars.ag.gov/) }}$

\subsection{Rainfall records}

Rainfall recorded in Gage 83 of the WS 103 was used for precipitation analysis. The records are available from 1963 till 2013. The precipitation data were recorded from two types of recording systems before and after 1999 in WGEW. The network consisted of analog- recording mechanical weighing rain gages (referred to as "analog") before 2000. From 1999, the digital-recording electronic weighing rain gages 
(referred to as "digital") were placed adjacent (1m-separation distance) to the analog gages and recorded the precipitation instead of the analog-recording rain gage. One year overlap of digital and analog data of 1999 are available in Gage 83. The digital-to-analog transition effects were adjusted based on this year of overlap.

\section{Methods}

\subsection{Rainfall characteristics and erosivity}

The number of events, peak 30-mins rainfall intensity (I30), number of significant events (the I30 that are larger than $25 \mathrm{~mm} / \mathrm{h}$ ), average event precipitation amount, average rainfall event duration, rainfall erosivity, I30 of significant rainfall event (Ir30), and rainfall kinetic energy were used to represent rainfall characteristics and energy dynamics.

In this study, rainfall erosivity $\left(\mathrm{MJ} \mathrm{mm} \mathrm{ha} \mathrm{m}^{-1} \mathrm{~h}^{-1} \mathrm{yr}^{-1}\right)$ is calculated as total $\mathrm{E}\left(\mathrm{MJ} \mathrm{ha}^{-1}\right)$ times $\mathrm{I} 30\left(\mathrm{~mm} \mathrm{~h}^{-1}\right)$. This product reflects the combined potential of rainfall impact and turbulence of runoff to transport detached soil particles from the field (Wischmeier and Smith, 1958). The E is calculated as:

$\mathrm{E}=\sum \mathrm{e}_{\mathrm{r}} \mathrm{v}_{\mathrm{r}}$

where $\mathrm{E}$ is the total kinetic energy, where $\mathrm{Vr}$ is the total volume of the rainfall and er is the kinetic energy:

$\mathrm{e}_{\mathrm{r}}=\mathrm{em}_{\mathrm{m}} *\left[1-\mathrm{a} * \exp \left(\mathrm{b} * \mathrm{i}_{\mathrm{r}}\right)\right]\left(\mathrm{MJ} \mathrm{mm}^{-1} \mathrm{ha}^{-1}\right)$

where em denotes maximum kinetic energy contents, $a$ and $b$ are empirical constants. The coefficient $a$, together with em determines rainfall energy attained at very low rainfall intensity. The coefficient $b$ 
determines how the kinetic energy approaches em with rainfall intensity. In this experience, em $=0.29$, $\mathrm{a}=0.72, \mathrm{~b}=-0.05$ (Brown and Foster, 1987).

\subsection{Visualizing long-term moving average trend.}

We firstly visualize 30-year moving average data of rainfall and rainfall erosivity. The 50 years of precipitation records were divided into 21 30-year climate periods (from the period: 1963-1992 to 19832012 with a one-year moving step (e.g., 1963-1992, 1964-1993, 1965-1994...). This 30-year analysis is in accordance with the recommended period length as a definition for climate of World Meteorological Organization (WMO, 2007). In addition, hydrological soil models such as WEPP needs at least 30 years of climate data to simulate stable soil erosion and runoff (Baffaut et al., 1995).

\subsection{Quantifying the influence of analogue-to-digital conversion to long term rainfall and erosivity variability analysis}

Keefer et al. (2008) compares annual rainfall characters. In their studies, the annual total depth and annual total duration are not affected by the analogue to digital conversion. However, their study does not include analyses on rainfall characters of each event (e.g. rainfall depth per event), which are closely transition on rainfall events, and the influence on the significant rainfall events, rainfall energy and erosivity. Specifically, we investigate the influence of analogue-to-digital conversion to: 1) the number of events, event duration, I30 per event, rainfall depth per event, and EI30 (E times I30) per event. 2) Ir30 and the number of events of significant rainfall events. We investigate the influence using the same linear regression method as was used in Keefer et al. (2008).

\subsection{Annual time series stability of and trend analysis}


A parametric and a nonparametric (i.e., distribution free) time series structural change methods were used to test the stability of the time series. These two methods were used for cross-validation purpose. The parametric method uses a moving cumulative (MOSUM) test of regression residuals that is implemented under an empirical fluctuation process (EFP, Zeileis 2003). Because the EFP assumes independent time series, an AR(1) integrated EFP model described in Lu et al., (2016) was used. The breakpoints will be located based on a method that iteratively minimizing sum of squared residuals to find the optimal location of the change (Bai1998, Bai2003, referred to as BP method) once the MOSUM test suggests a breakpoint in time series.

The non-parametric method is called ecp and was developed by James et al. (2013). The ecp method detects changes in marginal and joint distribution of multiple variables between time series segments using a weighted distant measure between two segments. A time series is iteratively segmented and tested with a permutation test to locate a change point (James et al. 2013). As the annual time series is unaffected by seasonality effects, the ecp method is suitable to be applied.

Afterwards, a general least square (GLS) model with an AR(1) model to account for serial correlation is applied to quantify the general trend of each stable time series segment as well as the whole time series.

\section{Results}

\subsection{Visualizing temporal trends of change in rainfall and rainfall erosivity}

The temporal variability of number of events, number of significant events, average event precipitation amount, average I30, average rainfall event duration, rainfall erosivity, average Ir30, and rainfall energy can be seen in Figure 2. Decreases in average event amount, average I30, average event duration, and 
rainfall energy are observed. The number of events increased. Average Ir30 and rainfall erosivity shows a drop from the $8^{\text {th }}$ period $(1971-2000)$ to the $14^{\text {th }}$ period $(1977-2006)$.

\subsection{Influence of digital-to-analogue conversion on event data and rainfall erosivity.}

Compared to the analogue system, the digital system is characterized by more events records and each event has shorter duration and less rainfall depth recorded. These are clearly shown in the trend of these variables in Figure 2. Our results show that the I30, Ir30 and EI30 are unaffected by the system conversion. The changes are listed below:

Table 1: Comparison of rainfall event data between analogue and digital systems of rainfall gauge 83 .

\begin{tabular}{|c|c|c|c|}
\hline & Analogue system & & Digital system \\
\hline Number of events & 51 & & 63 \\
\hline Average event duration (min) & $94 \min$ & & $66 \mathrm{~min}$ \\
\hline $\begin{array}{l}\text { Average Rainfall depth per } \\
\text { event (mm) }\end{array}$ & $5.54 \mathrm{~mm}$ & & $4.82 \mathrm{~mm}$ \\
\hline Number of significant events & 3 & & 3 \\
\hline Average $\operatorname{Ir} 30(\mathrm{~mm} / \mathrm{h})$ & 33.65 & & 34.88 \\
\hline $\begin{array}{l}\text { R square of I30 between two } \\
\text { systems }\end{array}$ & & 0.96 & \\
\hline $\begin{array}{l}\text { R square of EI30 between } \\
\text { two systems }\end{array}$ & & 0.97 & \\
\hline
\end{tabular}


Table 2: Comparing to the results of Keefer et al. (2008), I30 indicates peak 30 mins rainfall intensity, from analogue to digital system:

\begin{tabular}{lll}
\hline Rainfall characters & Keefer et al., 2008 & Our study \\
\hline Aggregated statistics & & \\
\hline & & \\
Annual total depth & unaffected & - \\
Number of significant events & - & unaffected \\
Annual total duration & unaffected & - \\
Annual I30 & unaffected & unaffected \\
Annual total events & - & More \\
\hline
\end{tabular}

Event statistics

\begin{tabular}{lll}
\hline & & \\
Event duration per event & - & shorter \\
Rainfall amount per event & - & less \\
Peak intensity per event, & $\begin{array}{l}\text { Influence of analogue- } \\
\text { to-digital conversion } \\
\text { diminishes over time, }\end{array}$ & \\
& $\begin{array}{l}\text { i.e., digital to analogue } \\
\text { effect: peak intensity }>\end{array}$ & \\
& peak 2min $>$ peak 5 & \\
& min $>$ peak 30min & \\
& - & unaffected \\
I30 of significant event (event & & \\
with I30 larger than $25 \mathrm{~mm} / \mathrm{min})$ & & unaffected \\
Erosivity (EI30) & - &
\end{tabular}



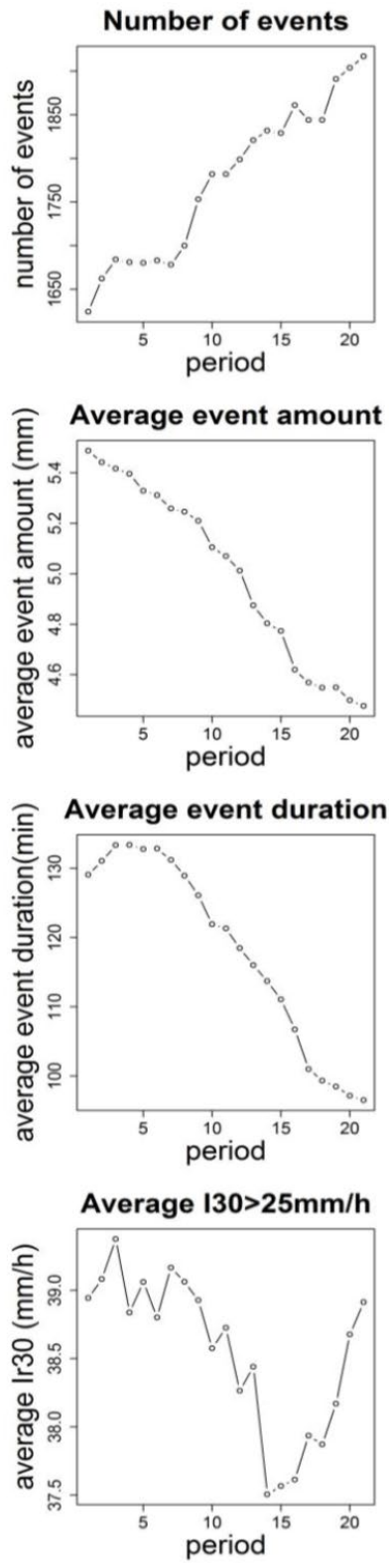

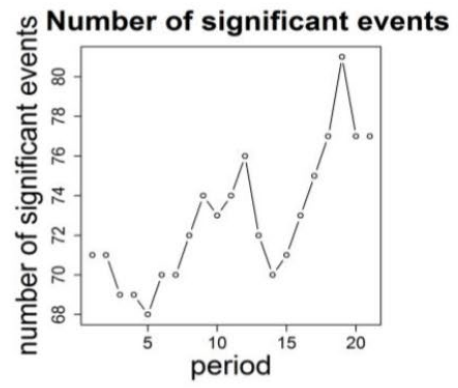

Average maximum $\mathbf{3 0}$ minutes rainfall intensity

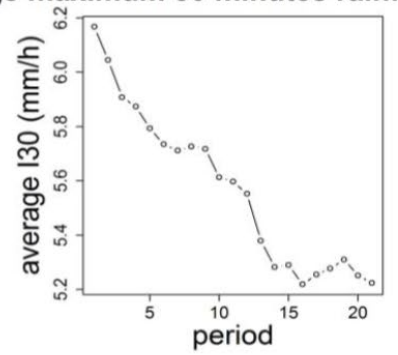

Rainfall erosivity of each periods
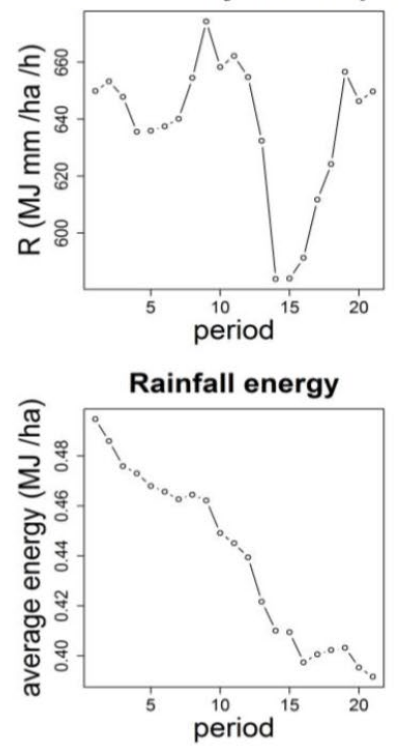

Figure 2 30-year moving window of rainfall characteristics and erosivity. 

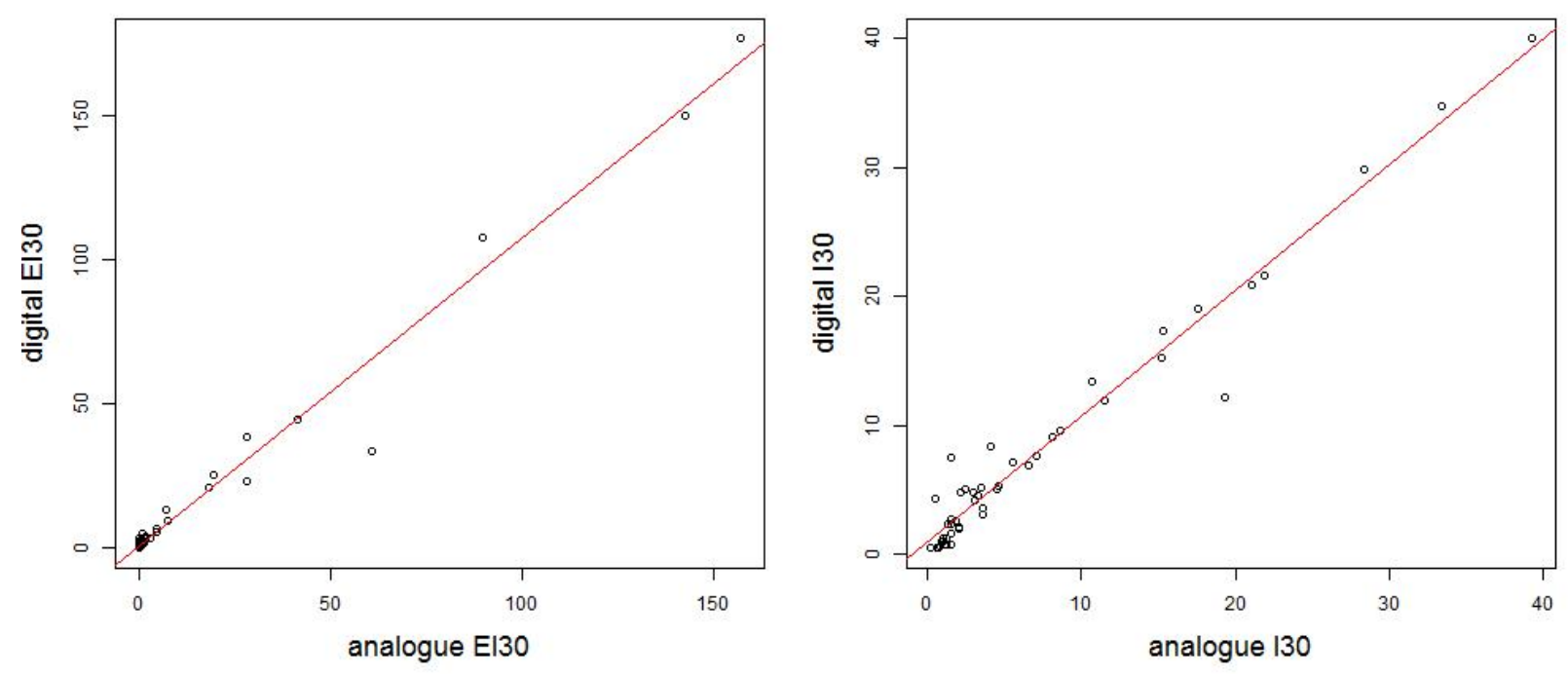

Figure 3 Comparison between analogue and digital system. Left: EI30, right: I30. The y-axes indicate digital system and the $\mathrm{x}$-axes indicate analogue system. The red lines are the 1:1 line.

\subsection{The variability of annual rainfall characteristics and rainfall erosivity}

The annual time series analyses show no trend for the rainfall amount, Ir30, and rainfall erosivity. Annual average rainfall energy and $\mathrm{I} 30$ both have downward trends. The EFP and ecp tests lead to the same results and indicate these trends are caused by abrupt changes occurred in the year 1992. Figure 7 shows the annual total I30 and rainfall energy stay stable, this explains the stable rainfall erosivity despite the change in annual average I30 and rainfall energy is because the annual total I30 (a) and E (b) also stays stable. 


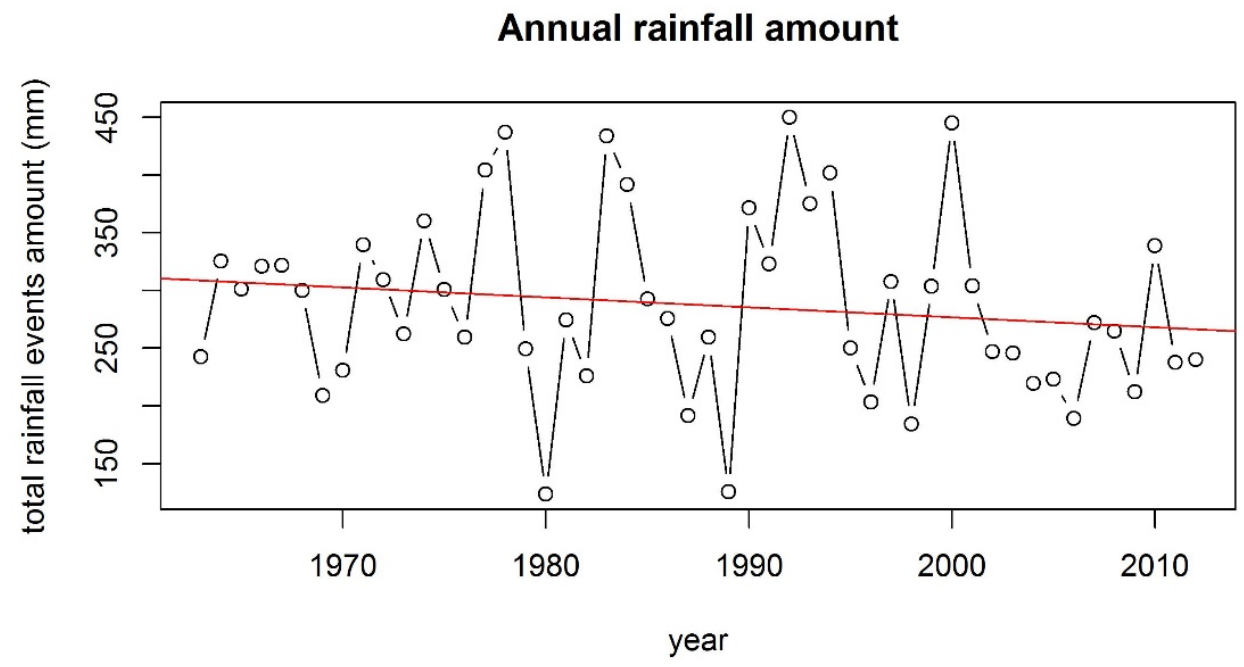

Figure 4. Annual total rainfall depth (1963 - 2012). The red line indicate regression line, which shows a slightly downwarding trend.

\section{Average Ir30}

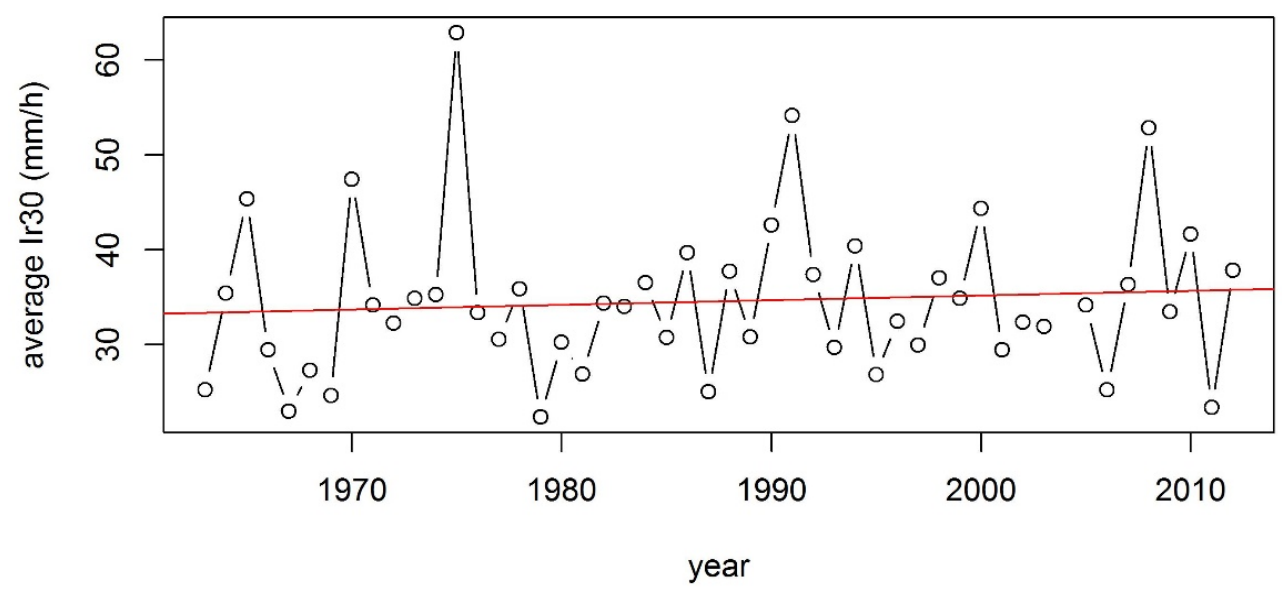

Figure 5. Annual average I30 with significant events (Ir30, 1963 - 2012), the red line indicates the regression line. 


\section{Annual rainfall erosivity}

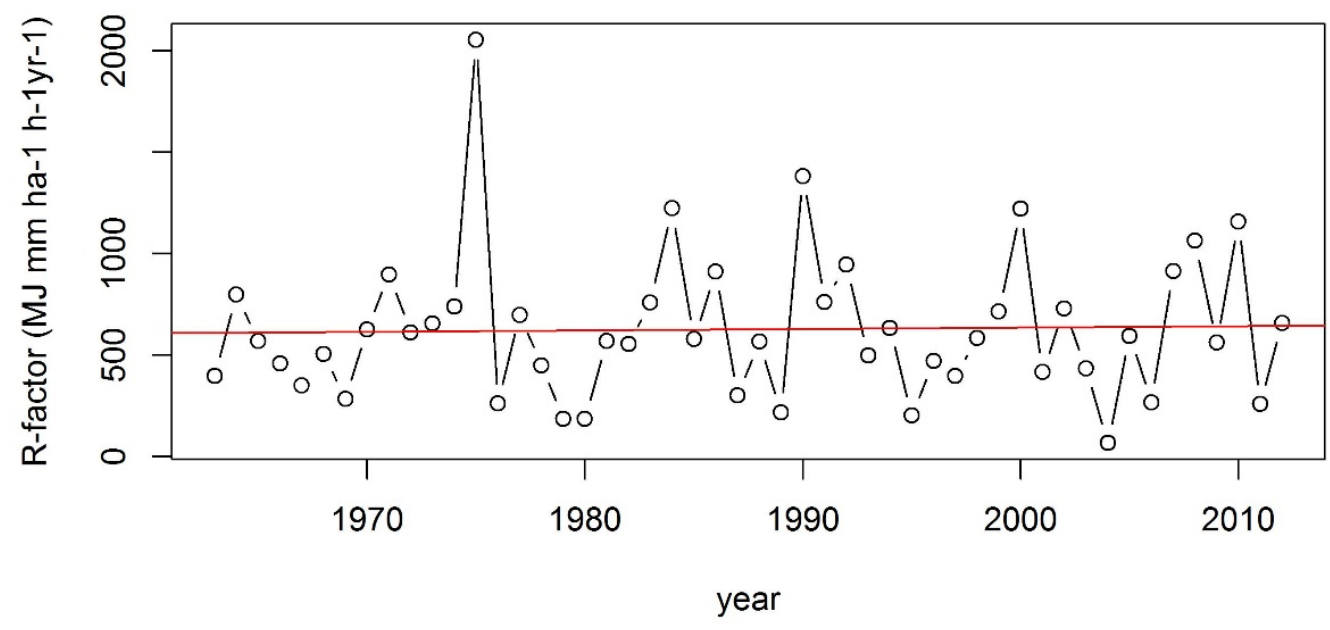

Figure 6. Yearly rainfall erosivity (1963 - 2012), the red line indicates the regression line.

\section{Number of significant events}

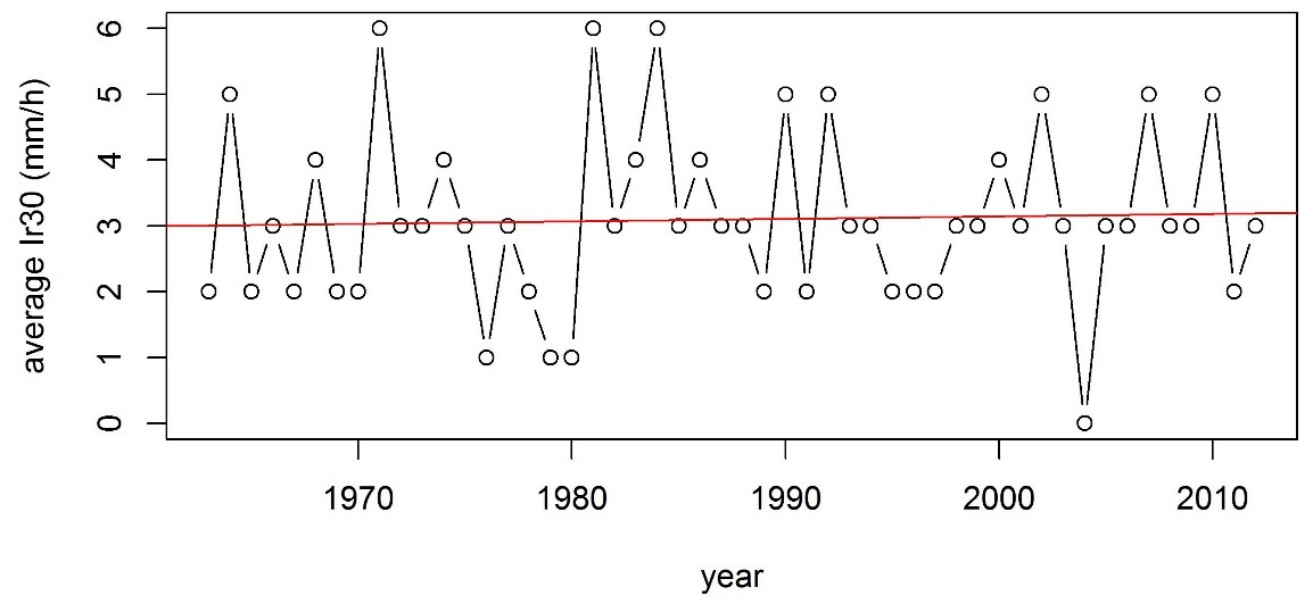

Figure 7. Number of significant events per year (1963 - 2012), the red line indicates the regression line. 


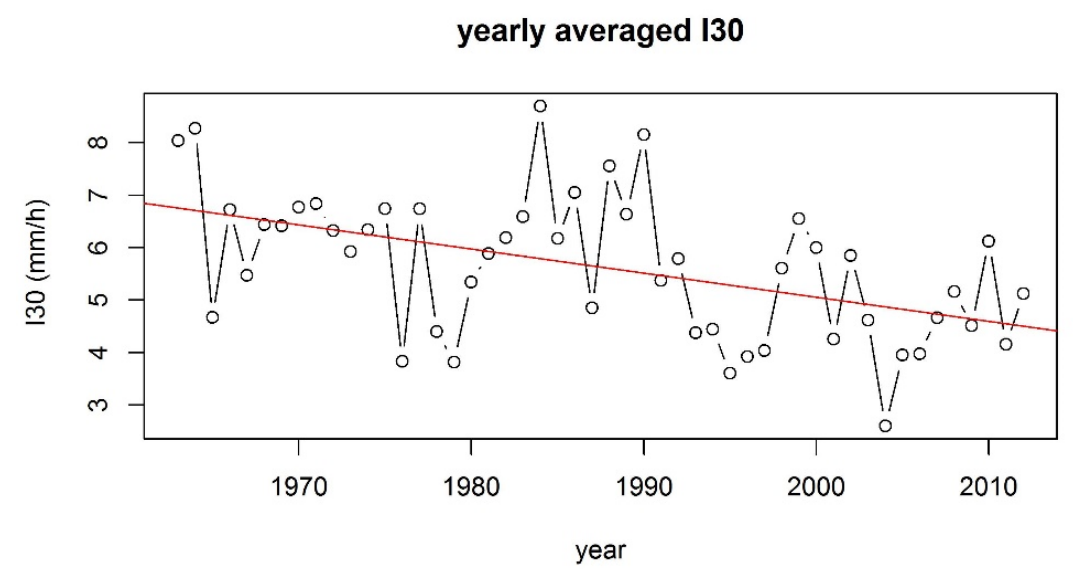

a

yearly average 130 with break point

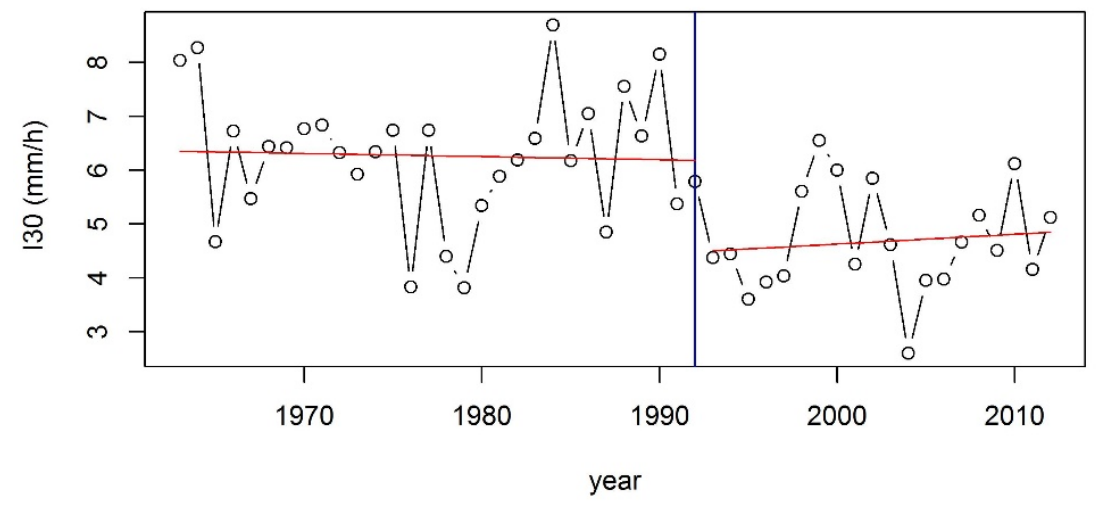

$\mathrm{b}$

Figure 8. (a) The linear regression analysis indicates average I30 has a downtrend. (b) The time series stability analysis detects a breakpoint in the time series at around 1992, indicating an abrupt change in the year 1992. Before and after the breakpoint there are no significant trends. 


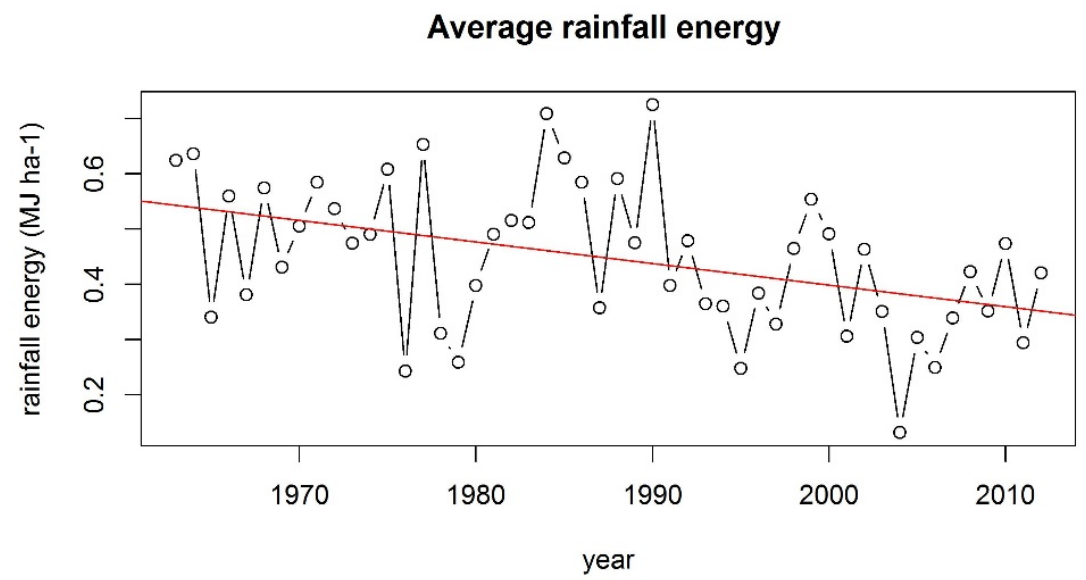

a

Average rainfall energy with a breakpoint

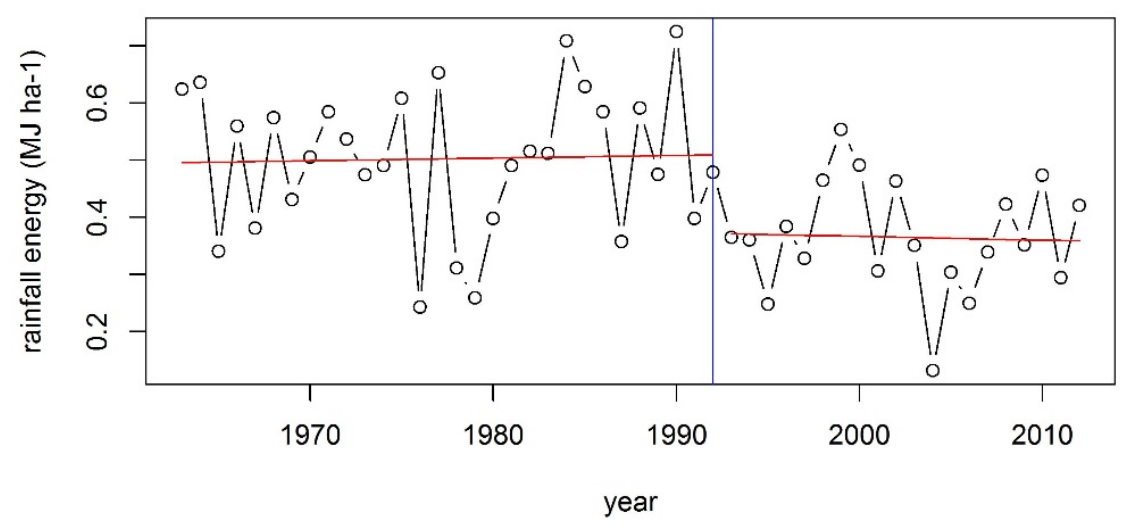

b

Figure 9: (a) The linear regression analysis indicates a downward trend of the average rainfall energy. (b) The time series stability analysis detects a breakpoint in the time series at around 1992, before and after the breakpoint the time series stays stable

$\mathrm{ab}$ 


\section{Discussion}

This study consists of three parts: 1) Visualizing the trends of rainfall characters using a long term moving window. 2) Understanding the impact of analogue-to-digital system conversion from the year 1999 to the long-term time series of rainfall characters. 3) Quantifying time series trends of annual rainfall events characters.

The benefit for using long-term climate instead of yearly analysis, in addition to being more fit for hydrological modeling, is that the averages of the long periods rule out weather variability and shows a significant trend of climate change. However, the transition from analogue to digital data significantly affects some of the rainfall character variables, particularly number of events and event duration. The differences between analog data and digital data were compared with an overlapping year of 1999 . The decreasing trends in average rainfall event amount and average rainfall event duration from a 30 years climate perspective are affected by the digital-to-analogue system conversion. The result was based on the assumption that this one-year is sufficient to represent the analog to digital transition of the other years. In any case, the differences from transitioning from analog to digital data should not be underestimated or omitted.

The rainfall energy and yearly averaged I30 are not affected by the digital-to-analogue system conversion. The time series structural change analyses indicate changes of the mean of time series in the year 1992. Before and after 1992 there is no trend in time series segments. These abrupt change occurred in 1992 did not affect rainfall erosivity, which shows no temporal trend during the whole study period. The reason that the rainfall erosivity is unchanged despite the change in annual average I30 and rainfall energy is 
because the annual total I30 and E stay stable. The decreasing trends of I30, rainfall energy indicated less rainfall intensity and less energy to detach soil on site.

Our study shows the Ir30 is also not affected by the digital-to-analogue system conversion, which is in consist with Keefer et al. (2008). Though there is no linear trend for rainfall erosivity and Ir30 for the whole 2130 -year climate periods, there are significant trends for the first 15 periods and last 6 periods, which indicate an increase in rainfall intensity when considering the year 2006 and beyond into account. The increasing trends of Ir30 of the last 6 periods indicate the increasing trend in rainfall intensity of extreme (or heavy) rainfall events for the latest periods. However, longer climate records are needed for the future trend of Ir30 to identify if the increase of Ir30 is due to the more extreme events. In addition, the sharp decrease of Ir30 from the $8^{\text {th }}$ period $(1971-2000)$ to the $14^{\text {th }}$ period $(1977-2006)$ may reflect the drought from the year 2000 - 2006. The curves of Ir30 and rainfall erosivity matched well with each other. These results may suggest that the effect of using the EI30 and using Ir30 alone as rainfall erosivity index is similar. This non-linear temporal dynamics of Ir30 and rainfall erosivity could not be observed with yearly climate analysis. The detected trends reflect the climate change onsite; however, periods longer than 50 years may be needed to quantify the trends of precipitation.

The parametric and non-parametric methods obtained the same results. The breakpoints are detected at the same time. As there is no other validation data, the same results obtained by statistically different methods indicate the breakpoints detected is reliable. The parametric model is theoretically more subject to serial correlation, the same results it obtained with the non-parametric model may indicate the insignificant influence of serial correlation in the time series for time series structural change detection. In addition, these two approaches are both successful owing to the lacking seasonality of annual time series. Further study can compare these two methods with monthly or finer temporal resolution time series. 


\section{Conclusion}

Precipitation data from the year 1963-2012 in Gage 83 on the WS103 watershed were used for precipitation trends analysis and the potential effects of climate change on soil erosion and runoff. The serial correlation and analog-to-digital transition effects on climate analysis were determined and adjusted. Our study extends from the study of Keefer et al. (2008) to event statistics. Ir30 and rainfall erosivity are highly correlated. A breakpoint is detected on yearly average I30 in 1992, which combining with the analyses of Keefer et al (2008) and our study that the analogue-to-digital system conversion is not a cause, may indicate an abrupt climate change. The change in I30 leads to the decrease of rainfall energy; however, the rainfall erosivity is more closely related to Ir30 and lacks temporal trend. 


\section{References}

Abrahams, A. D., J. P. Anthony and J. Wainwright (1995) Effects of vegetation change on interrill runoff and erosion, walnut-gulch, southern Arizona. Geomorphology, 13(1-4), 37-48.

Baffaut, C, M.A. Nearing, A.D. Nicks (1995) Impact of climate parameters on soil erosion estimated with CLIGEN and WEPP. American Society of Agricultural Engineers, 95-2577.

Bai, J. and Perron, P., 1998. Estimating and testing linear models with multiple structural changes. Econometrica, pp.47-78.

Bai, J. and Perron, P., 2003. Computation and analysis of multiple structural change models. Journal of applied econometrics, 18(1), pp.1-22.

Brown, L.C. and Foster, G.R. (1987) Storm erosivity using idealized intensity distributions. Transactions of the American Society of Agricultural Engineers, 30, 379-386.

Soil and Water Conservation Society (2003) Conservation Implication of Climate Change Soil Erosion and Runoff from Cropland: A Report from the Soil and Water Conservation Society.

Elliot, W. J., J. M. Laflen, A. W. Thomas and K. D. Kohl (1997). Photogrammetric and rillmeter techniques for hydraulic measurement in soil erosion studies. Transactions of the Asae, 40(1), 157-165.

Foster, G. R., F. Lombardi and W. C. Moldenhauer (1982). Evaluation of rainfall-runoff erosivity factors for individual storms. Transactions of the Asae, 25(1), 124-129.

Galton, A. (2008) Encyclopedia of GIS, chapter Processes and Events. Springer, 1 edition, 913-917.

Goodrich D. C. (1990) Geometric simplification of a distributed rainfall-runoff model over a range of basin scales. Ph.D. Dissertation, University of Arizona, Tucson, AZ. 
Goodrich D. C., Faures J.M., Woolhiser D.A., Lane L.J. and Sorooshian S. (1995). Measurement and analysis of small-scale convective storm rainfall variability. Journal of Hydrology 173, 283-308.

Goodrich, D. C., C. L. Unkrich, T. O. Keefer, M. H. Nichols, J. J. Stone, L. R. Levick and R. L. Scott (2008a) Event to multidecadal persistence in rainfall and runoff in southeast Arizona. Water Resources Research, 44(5).

Goodrich, D. C., T. O. Keefer, C. L. Unkrich, M. H. Nichols, H. B. Osborn, J. J. Stone, and J. R. Smith (2008b), Long-term precipitation database, Walnut Gulch Experimental Watershed, Arizona, United States. Water Resource Research, 44(5).

Hastings, R. H., and R. M. Turner (1980), The Changing Mile, 334. Univ. of Ariz. Press, Tucson.

IPCC Climate Change (2001), The Scientific Basis. Contribution of Working Group I to the Third Assessment Report of the Intergovernmental Panel on Climate Change [Houghton, J.T., Y. Ding, D.J. Griggs, M. Noguer, P.J. van der Linden, X. Dai, K. Maskell, and C.A. Johnson (eds.)]. Cambridge University Press, Cambridge, United Kingdom and New York, NY, USA, 881pp.

IPCC Climate Change (2007), The Physical Science Basis. Contribution of Working Group I to the Fourth Assessment Report of the Intergovernmental Panel on Climate Change [Solomon, S., D. Qin, M. Manning, Z. Chen, M. Marquis, K.B. Averyt, M.Tignor and H.L. Miller (eds.)]. Cambridge University Press, Cambridge, United Kingdom and New York, NY, USA.

Istok, J. D. and L. Boersma (1986). Effect of antecedent rainfall on runoff during low-intensity rainfall. Journal of Hydrology, 88(3-4), 329-342.

James, N.A. and Matteson, D.S., 2013. ecp: An R package for nonparametric multiple change point analysis of multivariate data. arXiv preprint arXiv:1309.3295.

Kruskal and Wallis (1952). Use of ranks in one-criterion variance analysis. Journal of the American Statistical Association, 47(260), 583-621. 
Keefer, T. O., C. L. Unkrich, J. R. Smith, D. C. Goodrich, M. S. Moran and J. R. Simanton (2008) An event-based comparison of two types of automated-recording, weighing bucket rain gages. Water Resources Research, 44(5).

Kiassari, E. M., D. Nikkami, M. H. Mahdian and E. Pazira (2012) Investigating rainfall erosivity indices in arid and semiarid climates of Iran. Turkish Journal of Agriculture and Forestry, 36(3), 365-378.

Kinnell, P. I. A. (2007) Runoff dependent erosivity and slope length factors suitable for modelling annual erosion using the Universal Soil Loss Equation. Hydrological Processes, 21(20), 2681-2689.

Lal, R. (1976) Soil erosion on alfisols in western nigeria. Geoderma, 16(5), 389-401.

Laflen, J. M., W. J. Elliot, D. C. Flanagan, C. R. Meyer and M. A. Nearing (1997) WEPP-predicting water erosion using a process-based model. Journal of Soil and Water Conservation, 52(2), 96-102.

Lu, M., Pebesma, E., Sanchez, A. and Verbesselt, J., 2016. Spatio-temporal change detection from multidimensional arrays: Detecting deforestation from MODIS time series. ISPRS Journal of Photogrammetry and Remote Sensing, 117, pp.227-236.

Ljung, G. M. and G. E. P. Box (1978) On a measure of a lack of fit in time series models. Biometrika, 65(2), 297-303

Meyer, C.R., C.S. Renschler, and R. C. Vining (2008) Implementing Quality Control on a Random Number Stream to Improve a Stochastic Weather Generator. Hydrological Processes, 22.8, 1069079.

McCarty, G., Y. Pachepsky, and J. Ritchie (2009) Impact of Sedimentation on Wetland Carbon Sequestration in an Agricultural Watershed. Journal of Environmental Quality, 38.2, 804-13.

Nearing, M. A., F. F. Pruski, M. R. ONeal (2004) Expected climate change impacts on soil erosion rates: A review. Journal of Soil and Water Conservation, 59, 43-50 
Nearing, A. M. (2001) Potential changes in rainfall erosivity in the U.S. with climate change during the 21 st century. Journal of Soil and Water Conservation, 56(3), 229-232.

Nearing, M. A., A. Kimoto, M. H. Nichols, M. H. and J.C. Ritchie (2005a) Spatial patterns of soil erosion and deposition in two small, semiarid watersheds. Journal of Geophysical Research-Earth Surface, 110(4), 11.

Nearing, M. A., V. Jetten, C. Baffaut, O. Cerdan, A. Couturier, M. Hernandez, Y. L. Bissonnais, M. H. Nichols, J. P. Nunes, C.S. Renschler, V. Souchère, and K. V. Oost (2005b) Modeling Response of Soil Erosion and Runoff to Changes in Precipitation and Cover. Catena, 61(2), 131-54.

Nearing, M. A, F. F. Pruski and M. R. ONeal (2004) Expected climate change impacts on soil erosionrates: A review. Journal of Soil and Water Conservation, 59(1), 43-50.

Nicks, A.D., L. J. Lane, and G. A. Gander (1995) Chapter 2, Weather Generator, In: (Flanagan, D.C., and M.A. Nearing, (eds.)) Hillslope Profile and Watershed Model Documentation. NSERL Report No. 10, USDA-ARS National Soil Erosion Research Laboratory, West Lafayette, IN.

Nichols, M. H., K. G. Renard and H. B. Osborn (2002) Precipitation changes from 1956 to 1996 on the Walnut Gulch Experimental Watershed. Journal of the American Water Resources Association, $38(1), 161-172$.

Nunes, J. P., J. Seixas, J. J. Keizer and A. J. D. Ferreira (2009) Sensitivity of runoff and soil erosion to climate change in two Mediterranean watersheds. Part I: model parameterization and evaluation. Hydrological Processes, 23(8), 1202-1211.

Osborn, H. B. and L. Lane (1969) Precipitation-runoff relations for very small semiarid rangeland watersheds. Water Resources Research, 5(2), 419.

Pruski, F. F. and M. A. Nearing (2002) Runoff and soil-loss responses to changes in precipitation: A computer simulation study. Journal of Soil and Water Conservation, 57(1), 7-16. 
Renschler, C. S. (2003) Designing geo-spatial interfaces to scale process models: the GeoWEPP approach. Hydrological Processes, 17(5), 1005-1017.

Renschler, C. S. and T. Lee (2005) Spatially distributed assessment of short- and long-term impacts of multiple best management practices in agricultural watersheds. Journal of Soil and Water Conservation, 60(6), 446-456.

Rosenzweig, C. and D. Hillel (1998) Climate change and the global harvest: Potential impacts of the greenhouse effect on agriculture.

Ritchie, J. C., M. A. Nearing, H. M. Nichols, and C. A. Ritchie (2005) Patterns of Soil Erosion and Redeposition on WS103 Watershed, Walnut Gulch Experimental Watershed, Arizona. Catena, 61(2-3), 122-30.

Renard, B, M. Lang, P. Bois, A. Dupeyrat, O. Mestre, H. Niel, E. Sauquet, C. Prudhomme, S. Parey, E. Paquet E, L. Neppel L, J. Gailhard (2008a) Regional methods for trend detection: Assessing field significance and regional consistency. Water Resources Research 44.

Renard, K.G., M. H. Nichols M.H., D. A. Woolhiser, H. B. Osborn (2008b) A brief background on the U.S. Department of Agriculture - Agricultural Research Service Walnut Gulch Experimental Watershed. Water Resources Research 44, 11.

Stone, J. J., M. H. Nichols, D. C. Goodrich and J. Buono (2008) Long-term runoff database, Walnut Gulch Experimental Watershed, Arizona, United States. Water Resources Research, 44(5).

Van Dijk, A., L. A. Bruijnzeel and C. J. Rosewell (2002) Rainfall intensity-kinetic energy relationships: a critical literature appraisal. Journal of Hydrology, 261(1-4), 1-23.

Wischmeier, W. H., and Smith, D. D. (1958) Rainfall energy and its relationship to soil loss. Trans. AGU $39,285-291$. 
Zeileis, A., Kleiber, C., Krämer, W. and Hornik, K., 2003. Testing and dating of structural changes in practice. Computational Statistics \& Data Analysis, 44(1), pp.109-123.

Zhang, X.-C., M.A Nearing, J.D. Garbrecht, and J.L. Steiner (2004) Downscaling Monthly Forecsasts to Simulate Impacts of Climate Change on Soil Erosion and Wheat Production. Soil Sci Am. J. 68, 1376-1385.

Zhang, Y., M. Hernandez, E. Anson, M. Nearing, H. Wei, J. J. Stone, and P. Heilman (2012) Modeling Climate Change Effect on Runoff and Soil Erosion in Southeastern Arizona Rangelands and Implication for Mitigation with Conservation Practices. Journal of Soil and Water Conservation 67.5

Zhang, X.-C., W.-Z. Liu, Z. Li, and F.-L. Zheng (2009) Simulating Site-specific Impacts of Climate Change on Soil Erosion and Surface Hydrology in Southern Loess Plateau of China. Catena, $79(3), 237-42$.

Zhang, X.-C. (2004) Calibration, Refinement, and Application of the WEPP Model for Simulating Climatic Impact on Wheat Production. Transactions of the Asae, 47(4), 1075-085.

Zhang, X.-C., W.-Z. Liu, Z. Li, and J. Chen (2011) Trend and Uncertainty Analysis of Simulated Climate Change Impacts with Multiple GCMs and Emission Scenarios. Agriculture and Forest Meteorology, 151, 1297-304.

Web access

U-Idaho, Rangeland program, < http://www.webpages.uidaho.edu/what-is-range/ > Accessed by April, 2013

EPA, Watersheds, < http://water.epa.gov/type/watersheds/whatis.cfm > Accessed by April, 2013

USDA-ARS, Southwestern Watershed Research Center, < http://www.tucson.ars.ag.gov/ > Accessed by April, 2013 
Surface Station Database, <http://www.appinsys.com/globalwarming/Tombstone.htm>Accessed by April, 2013

SWRC (2011) Walnut Gulch Experimental Watershed, AZ, USA, $<$ http://www.ars.usda.gov/SP2UserFiles/Place/53424500/WGBrochure.pdf>Accessed by March, 2013

WMO (2007) The Role of Climatological Normals in a Changing Climate, $<$ http://www.wmo.int/pages/prog/wcp/wcdmp/documents/WCDMPNo61.pdf $>$ Accessed by March, 2013 